\title{
Zinc or vitamin A reduced diarrhoea in young, poor Bangladeshi children
}

Rahman MM, Vermund SH, Wahed MA, et al. Simultaneous zinc and vitamin A supplementation in Bangladeshi childen: randomised double blind controlled trial. BMJ 2001 Aug 11;323:314-8.

\section{QUESTION: In young, poor children in Bangladesh, does supplementation with zinc or vitamin $\mathrm{A}$, or both, reduce diarrhoea and acute lower respiratory infection (LRI)?}

Design

Randomised (allocation concealed*), blinded (clinicians, patients, outcome assessors, and statisticians), ${ }^{*}$ placebo controlled trial with 6 months of follow up.

\section{Setting}

Urban slums in Dhaka, Bangladesh.

\section{Patients}

800 children who were 12 to 35 months of age were enrolled. Exclusion criteria were receipt of a vitamin A capsule in the previous 4 months or severe malnourishment. 665 children (83\%) (mean age 24 mo, 53\% boys) completed the trial.

\section{Intervention}

Children were allocated to zinc syrup (20 mg of elemental zinc), $5 \mathrm{ml} /$ day ( $\mathrm{n}=170)$; vitamin $\mathrm{A}, 200000 \mathrm{IU}$ $(\mathrm{n}=159)$; zinc plus vitamin A $(\mathrm{n}=175)$; or placebo $(\mathrm{n}=161)$. Zinc or placebo syrup was given for 14 days, and on day 14 patients received a vitamin A or placebo capsule.

\section{Main outcome measures}

Diarrhoea ( $\geqslant 3$ watery stools in $24 \mathrm{~h}$ or blood in the stools) and acute LRI (cough, difficult or rapid breathing, and fever).

\section{Main results}

Children who received zinc or vitamin A had a reduced incidence of diarrhoea (table). No interaction existed between zinc and vitamin $\mathrm{A}$ in reducing the incidence (rate ratio $1.07,95 \%$ CI 0.91 to 1.277 ) or prevalence (rate ratio 1.08, CI 0.99 to 1.17) of diarrhoea. However, zinc in combination with vitamin A reduced the prevalence of persistent diarrhoea (diarrhoea lasting $\geqslant 14 \mathrm{~d}$ ) (rate ratio 0.79 , CI 0.66 to 0.94 ) and dysentery (blood and mucus in stools) (rate ratio 0.80 , CI 0.67 to 0.95 ). The incidence of acute LRI was increased in children who received zinc but not in those who received vitamin $\mathrm{A}$ (table). The interaction between zinc and vitamin A reduced the prevalence of acute LRI (rate ratio 0.58 , CI 0.46 to 0.73 ) but not the incidence (rate ratio 0.75 , CI 0.46 to 1.20$)$.
Zinc or vitamin A v placebo for incidence of diarrhoea in young children $\dagger^{-}$

\begin{tabular}{llll} 
Outcomes at 6 months & Comparison & $\begin{array}{l}\text { Rate ratio } \\
(95 \% \mathrm{Cl})\end{array}$ & NNT \\
\hline Diarrhoea (all types) & Zinc $v$ placebo & $0.89(0.79$ to 0.99$)$ & 2 \\
\hline & Vitamin A $v$ placebo & $0.84(0.74$ to 0.94$)$ & 2 \\
\hline & & NNH & \\
\hline $\begin{array}{l}\text { Acute lower } \\
\text { respiratory infection }\end{array}$ & Zinc $v$ placebo & $1.62(1.16$ to 2.25$)$ & 6 \\
\hline & Vitamin A $v$ placebo & $1.06(0.74$ to 1.53$)$ & Not significant \\
\hline
\end{tabular}

†Abbreviations defined in glossary; NNT and NNH calculated from data in article.

\section{Conclusions}

In young, poor children in Bangladesh, supplementation with zinc or vitamin A reduced diarrhoea. Zinc increased the incidence of acute lower respiratory infection, but this adverse effect was offset by the interaction of zinc and vitamin A, which reduced the prevalence of acute lower respiratory infection.

*See glossary.

\section{COMMENTARY}

The effect of micronutrients, particularly zinc and vitamin A, on morbidity and mortality in children is being increasingly recognised. A combination of zinc and vitamin A was better than vitamin $\mathrm{A}$ alone in improving blood concentrations of vitamin $\mathrm{A}$, suggesting interaction between the 2 micronutrients. ${ }^{1}$ Whether zinc alone is inferior to the combination is not clear.

Vitamin A has been shown to be responsible for the integrity of the respiratory epithelium through several mechanisms and has a definite beneficial effect in reducing mortality in children with pneumonia. ${ }^{2}$ The evidence for reducing morbidity is not as clear. Zinc has been found to act on the epithelium and on absorption mechanisms to reduce diarrhoea. Zinc supplementation reduces overall mortality and improves growth in high risk paediatric populations. ${ }^{3}$

The findings of the study by Rahman et al show that whereas vitamin A has limited effects in reducing morbidity from both diarrhoea and acute LRI, zinc may actually increase acute LRI morbidity. Another community based randomised trial in South India has not shown any effect of vitamin A on acute LRI or diarrhoea. ${ }^{4}$

Clearly, these interventions need to be studied further. The literature is voluminous but inconclusive. A biological basis exists for the reduction in mortality and morbidity with zinc and vitamin A, but the evidence for benefit and harm in sick children remains inconclusive. Diarrhoea and respiratory infections have rarely been studied in the same population at the same time. Furthermore, the effect of the simultaneous administration of zinc and vitamin $\mathrm{A}$ has not been thoroughly studied. More research is needed before zinc and vitamin A can be accepted as public health intervention measures for childhood illness.

Manjula Datta, MD, DCH, MSc Tamil Nadu Medical University Chennai, Tamil Nadu, India

1 Christian P, West KP Jr. Interactions between zinc and vitamin A: an update. Am J Clin Nutr 1998;68:435S-41S.

2 The Vitamin A and Pneumonia Working Group. Potential interventions for the prevention of childhood pneumonia in developing countries: a meta-analysis of data from field trials to assess the impact of vitamin A supplementation on pneumonia morbidity and mortality. Bull World Health Organ 1995;73:609-19.

3 Marshall I. Zinc for the common cold. Cochrane Database Syst Rev 2000;(2):CD001364

4 Venkatarao T, Ramakrishnan R, Nair NG, et al. Effect of vitamin A supplementation to mother and infant on morbidity in infancy. Indian Pediatr 1996;33:279-86. 